\title{
No pets allowed: A trans-species social justice perspective to address housing issues for older adults and companion animals
}

\author{
Atsuko Matsuoka1, John Sorenson², Taryn Mary Graham¹, Jasmine Ferreira'
}

\section{ABSTRACT}

INTRODUCTION: Significant benefits of companion animals (i.e., pets) for older adults are recognized and publications on Animal-Assisted Intervention, Animal-Assisted Activities and Animal-Assisted Therapies with older adults are growing. Studies on housing and communityresiding older adults with companion animals from a non-utilitarian perspective on other animals, however, are rather limited.

METHODS: For this scoping review, we used a Critical Animal Studies perspective, in particular, a trans-species social justice framework to address two questions: "What are the scope and size of the literature on housing for community living older adults with companion animals?" and "What is known from the existing literature?" We searched peer-reviewed publications from 1980 to 2019 by using MEDLINE, PsychINFO, ProQuest and Scopus.

FINDINGS: Six works from Canada, Aotearoa New Zealand and US met our criteria. A disturbing reality was discovered: Restrictive leasing ('no pets' for rental housing) among low-income older adults with companion animals in public housing has persisted for the last 40 years and prevents them from accessing affordable housing. Also, the discourse of pets as problems or risk seems to justify prohibiting older adults from living with companion animals.

CONCLUSION: Utilising the concept of speciesism and a trans-species social justice framework for analysis, we argue that intersectional institutional oppression of speciesism and classism is a root cause of the situation. Justice for older adults cannot be achieved without justice for their companion animals. Future studies in human-animal relations and education and practice in social work need to incorporate ideas of speciesism and justice beyond humans.

KEYWORDS: Housing; companion animals; pets; aging; trans-species social justice; Critical Animal Studies; human-animal relations

Examination of housing and aging is typically conceptualised solely in relation to humans; however, this may provide an incomplete picture. In some situations, companion animals (i.e., pets) may be the only stable, long-term, significant relationships in the lives of older adults. Yet housing issues of older adults continue to be conceptualised within an anthropocentric paradigm. Most social workers do not include any questions about companion animals, for example, in home care
1 York University, Canada

2 Brock University, Canada
AOTEAROA

NEW ZEALAND SOCIAL WORK 32(4), 55-68.

CORRESPONDENCE TO: Atsuko Matsuoka atsukom@yorku.ca 
assessments, which is problematic when considering that the majority of households in North America today include companion animals. In the US, a 2019/2020 survey of pet owners found that the number of US households with a companion animal increased from $62 \%$ to $67 \%$ since 2010 , from 71.4 million pet-owning homes, to 84.9 million (American Pet Products Association, 2020). A Canadian survey found similar growth in pet ownership, with an estimated $10 \%$ increase in cat and dog ownership in the past 10 years (Canadian Animal Health Institute, 2019). A global survey in 2015 cites $61 \%$ of Canadians owning at least one companion animal (Growth from Knowledge, 2015). In other words, most Canadians and Americans have companion animals and having companion animals is no longer an exception but a norm in the 21st century in these countries. Many who live with companion animals consider them as family. These changes in perceptions of and experiences within families suggest social work practitioners and educators in this century need to reconsider the current anthropocentric paradigm and professional ethical commitment (Ryan, 2011). The purpose of this paper is to discuss key findings from a scoping review study on housing and non-institutionalised older adults living in communities with companion animals from a Critical Animal Studies perspective, specifically a transspecies social justice framework (Matsuoka \& Sorenson, 2014, 2018; Sorenson \& Matsuoka, 2019). By doing so, we will bring the core social work value, social justice, to the centre of discussion on human-animal relations. Some concepts are likely new to social work readers and we begin this paper by defining these.

\section{Critical animal studies}

Critical Animal Studies is an interdisciplinary field of study which challenges anthropocentrism, recognises nonhuman animals as beings with agency, personhood and subjectivity, whose lives are intrinsically valuable and respects their autonomy and dignity. It challenges a human-animal binary and rejects not only the cruel treatment of other animals but their use as resources or tools for human ends. Importantly, it opposes the systemic and institutionalised exploitation of nonhuman animals and supports efforts to liberate them from oppressive conditions by taking an intersectional perspective (Nocella, Sorenson, Socha, \& Matsuoka, 2014).

\section{Trans-species social justice and speciesism}

Social justice is the core concept of the social work profession and it is widely accepted in relation to class, gender, race, age, sexual orientation, ability, and so on, but the profession has been slow to acknowledge that species is equally important. The term speciesism was coined in 1970 by clinical psychologist Richard Ryder (1983) and popularized by Peter Singer's (1975) book, Animal Liberation. The term refers to an ideology which supports treating sentient and morally equivalent beings differently on the basis of species alone, rather than giving them equal consideration. Many works on human-animal relations focus on individuals and are indifferent to speciesism completely or to the structural nature of speciesism. Critical Animal Studies scholars, such as Nibert $(2002,2013)$ and Sorrenson $(2010,2016)$ examined intertwined systemic oppression by using a political economy approach and ecofeminists Adams (2010, 2014), Donovan (2018), Gruen (2007), and Kheel (2008) investigate the intertwined oppression of women and nonhuman animals, i.e., patriarchy and speciesism.

We created the term trans-species social justice to highlight the importance of social justice in addressing human-animal relations, which is core to Critical Animal Studies, but also to social work. It refers to the "consideration of interests of all animals (including humans) in order to achieve institutional conditions free from oppression and domination" (Matsuoka \& Sorenson, 2014, p. 70). This concept helps bring in an 
examination of structural issues, whereas the dominant trend is to examine individual relationships. We believe that this also helps social workers reflect on human-centred practice and policy.

\section{Literature review}

Most studies related to animals and older adults are on animal-assisted interventions (AAI), animal-assisted activities (AAA), and animal-assisted therapies (AAT). Many conducted these studies with older adults in long-term care or retirement homes (e.g., Kogan, 2001; Le Roux \& Kemp, 2009). Research on community-living older adults focuses mainly on the health benefits gained from companion animals (e.g., KrauseParello \& Kolassa, 2016). The most recent systematic review on older adults and animals found that, although the effect on cognitive functioning among residents with dementia or Alzheimers disease in a longterm care setting is inconsistent, close to $80 \%$ of relevant studies reported positive mental and physical health outcomes of having companion animals, based on the respective aspects they measured (Hughes, Verreynne, Harpur, \& Pachana, 2020). As benefits of animal companionship for older adults are increasingly understood, its potential as an intervention strategy is being recognised (Gee \& Mueller, 2019). Thus, companionship with other animals is frequently conceptualised as a means to enhance the quality of human life, although more now acknowledge the importance of considering the welfare of animals as well (e.g., Gee \& Mueller, 2019; Hughes et al., 2020). Aside from such works, a smaller number of studies focus on issues such as grief and loss of pets (Laing \& Maylea, 2018; Morley \& Fook, 2005), elder abuse (Boat \& Knight, 2001; Peak, Ascione, \& Doney, 2012), end of life care (Dorfman, Denduluri, Walseman, \& Bregman, 2012; Engelman, 2013; Geisler, 2004), and animal hoarding (Koenig, Leiste, Spano, \& Chapin,2013; Nathanson, 2009). Still others encourage social workers to include companion animals in geriatric practice as hard-to-reach older clients may accept visits by social service agencies if they help them to care for companion animals (Ebenstein \& Wortham, 2001) or to promote food security and health among older companion animal owners by including pet food in local foodbanks (Rauktis et al., 2020). However, studies that conceptualise other animals not as tools to benefit human animals and examine animal companionship among community-dwelling older adults in relation to housing seem to be limited; this important topic requires closer investigation and our scoping review set out to locate existing work.

\section{Method}

Arksey and O'Malley's (2005) approach was adopted to conduct a scoping review to address two research questions: "What are the scope and size of the literature on housing for community living older adults with companion animals?" and "What is known from the existing literature?" We defined "older adults" as over 65 years of age but we accepted some studies that defined them differently; "companion animals" as any dog, cat, or other animal kept for companionship, as opposed to livestock, laboratory animals, working animals, therapy animals, or sport animals, which may be kept for other reasons; finally, "housing" as privately owned or both private and public rental housing. We excluded emergency shelters, assisted living residences and long-term care accommodations.

\section{The search}

In order to identify relevant studies, we began with electronic databases. We first searched MEDLINE, PsychINFO, ProQuest and Scopus. The following keywords were combined for the searches: keywords related to housing ("housing OR home OR accommodation OR residential OR rental OR tenants OR landlords"); keywords related to older adults ("older adults OR seniors OR elderly OR aging") and keywords related to companion animals ("pets OR companion animals OR dogs OR cats"). We 
used keywords related to the human-animal field ("human-animal studies OR humananimal bond OR human-animal interaction OR human-animal relations") in place of keywords related to companion animals, which yielded similar articles and no new citations. Using ProQuest, which includes over 50 databases, we identified databases with many relevant works such as Sociology Collection, Social Sciences Abstracts, Applied Social Sciences Index and Abstracts, Social Services Abstracts, and Sociological Abstracts. We then searched these databases individually, including additional terms for three key areas (i.e., older adults, housing and companion animals) by using their thesauruses. However, no additional work was found. We repeated these processes three times (April and October 2019 and May 2020) and obtained similar results. Then, using the same key terms, we searched specific journals which came up frequently, such as Gerontologist, Journal of Gerontological Social Work, and Ageing and Society. We also searched Canadian Journal on Aging to ensure we did not miss Canadian publications which may be relevant for future research. Again, these searches did not yield any new citations. We concluded that our search was comprehensive. The paper is based on our May 2020 search using the selection criteria listed below.

\section{Selection}

Using the keywords listed earlier in MEDLINE, PsychINFO, ProQuest and Scopus we found in 323 citations in total. We added 13 articles known to the authors. Studies were not excluded based on their methods, nor on any assessment of their methodological rigour. Our inclusion criteria were as follows and we excluded those which did not meet them:

Publication period: 1980 to fall 2019

Language: English

Type of work: Peer-reviewed journal articles based on empirical studies
Focus: Non-institutionalised older adults living in communities with companion animals or those who wish to live with them and housing.

We removed duplications and those focused on health-related outcomes such as allergies or respiratory symptoms, those that focused on pets as threats or nuisances such as problems with barking dogs, cat bite wounds, zoonoses or the health of older companion animals and veterinary care. We also removed citations whose focus was on assessing outcomes of AAI, AAT, or AAA. We excluded studies on robots in place of AAI, AAT or AAA. Those that addressed use of animals in long-term care settings were excluded. As a result, we removed 299 citations in total at the first screening stage based on titles by using the inclusion criteria. We kept 37 articles to further review their titles and abstracts. We removed those which had limited focus on independent living older adults and housing. We selected 26 articles. When their references were checked, six were added as potential citations. We further conducted back searches by utilising Google Scholar and Worldcat to identify articles which cited these 32 selected works. No work met our inclusion criteria from the back search. Thirty-two articles were used for full review. After the full review, we removed those on temporary shelter (neither owned nor rental housing, such as emergency shelters), care homes, commentaries or those which were not based on original empirical studies. Six articles met our final inclusion criteria to chart (Figure 1).

\section{Results}

This scoping review identified six relevant works which met our criteria. Half were published in the 1980s, only one in the 1990s and none in the 2000s; two found in the 2010s were by the same lead author. Four considered situations in the US, two in Canada and one in Aotearoa Zealand. All are descriptive studies. Recent studies are all qualitative with smaller sample sizes and two qualitative studies and one mixed 
Screened by titles

Database and journals searched: 323

Scopus: 132, ProQuest: 154,

PsychINFO: 21, MEDLINE: 16

Known to authors: 13

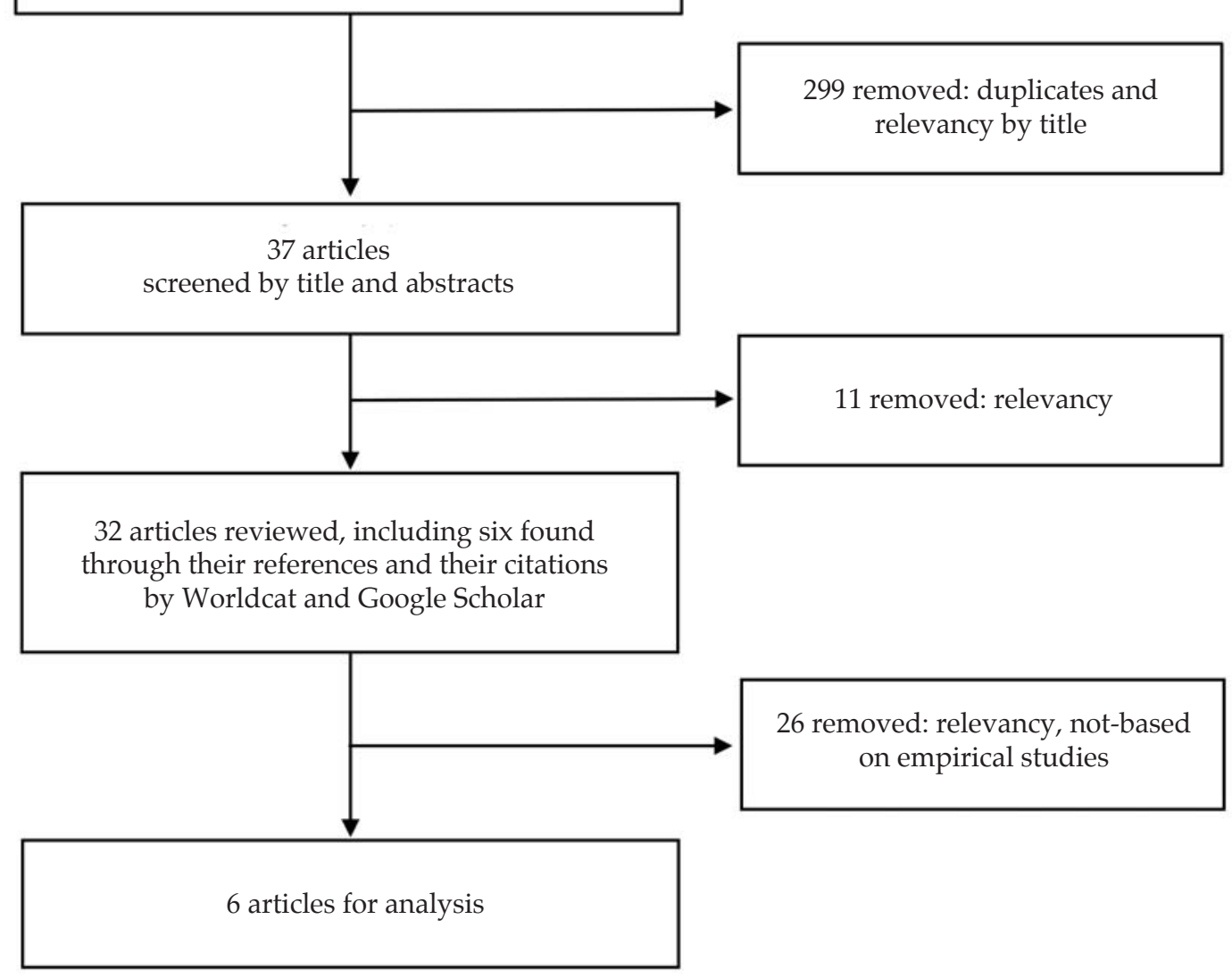

Figure 1: Scoping Review Flowchart.

method study were published in the 1980s and 1990s (Table 1).

\section{The scope of the studies found}

We identified three key characteristics of the scope of the articles on housing provision for older adults living with companion animals. The first characteristic is their focus on housing for low-income older adults. Second, they all examined attitudes and attachments to pets in various ways. As to methods, surveys, a comparative study method, case study, or multiple qualitative methods were used. For perspectives, some were from those of older pet owners and non-pet owners, and others explored those of professionals, such as property managers and service providers of pets in the buildings. For example, one examined whether non-pet owners accept pets in their housing complex through comparative study of two cities in Aotearoa New Zealand: in one city, where older adults can have companion cats and, in another city, where they could not (Mahalski, Jones, \& Maxwell, 1988). Earlier work examined both older pet owners, other residents, and property managers through surveys and interviews (Hart \& Mader, 1986). A third characteristic 


\begin{tabular}{|c|c|c|c|c|c|c|}
\hline $\begin{array}{l}\frac{7}{0} \\
\frac{0}{0} \\
\frac{2}{\circ} \\
\frac{9}{8}\end{array}$ & $\begin{array}{l}0 \\
\frac{0}{0} \\
\frac{0}{2} \\
\frac{0}{0} \\
\frac{0}{2} \\
0 \\
\frac{0}{2} \\
\frac{1}{2}\end{array}$ & 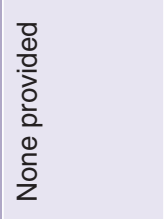 & 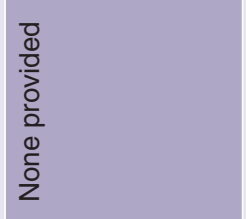 & 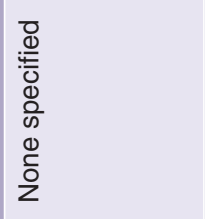 & $\begin{array}{l}0 \\
0 \\
\frac{\pi}{0} \\
\frac{0}{1} \\
\frac{1}{1} \\
0 \\
. \frac{1}{0} \\
\frac{0}{4}\end{array}$ & 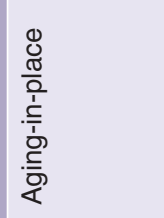 \\
\hline 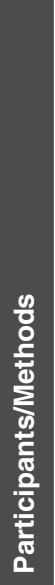 & 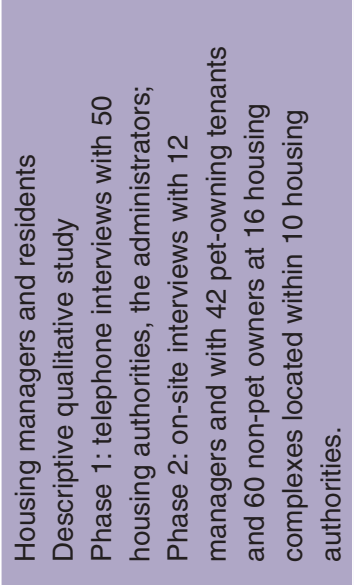 & 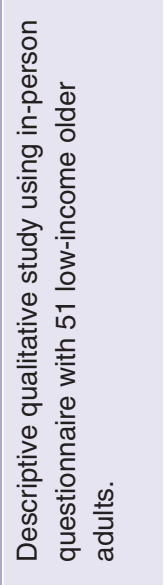 & 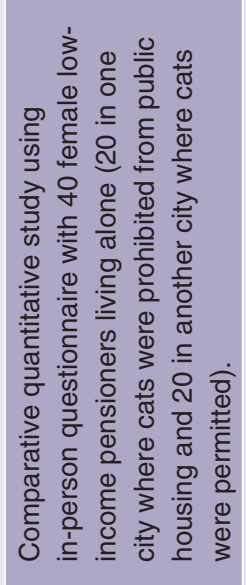 & 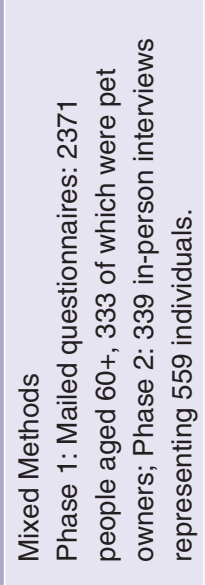 & 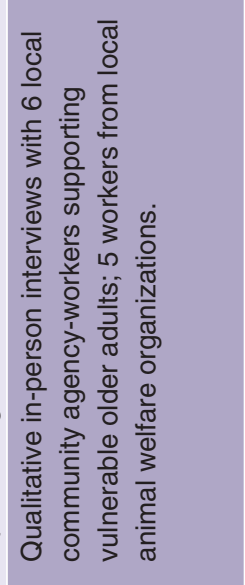 & 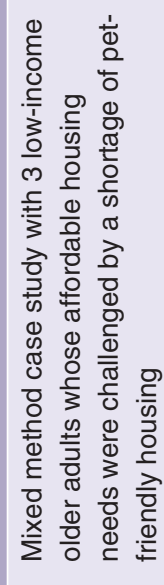 \\
\hline 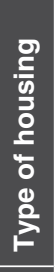 & 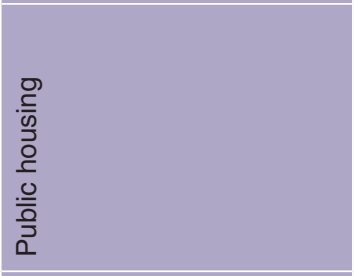 & 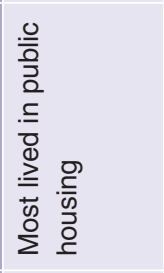 & 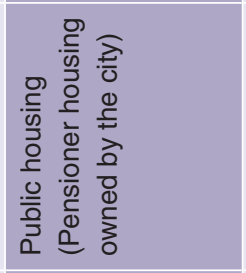 & 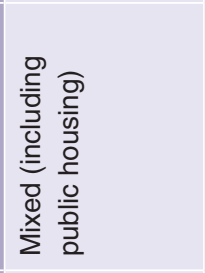 & 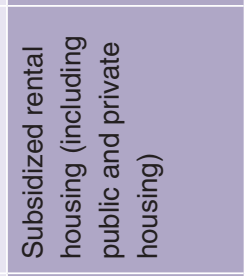 & 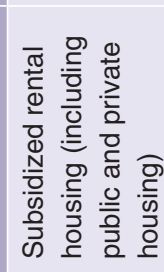 \\
\hline $\begin{array}{l}\$ \\
\& \\
\circ \\
\text { 을 } \\
2\end{array}$ & 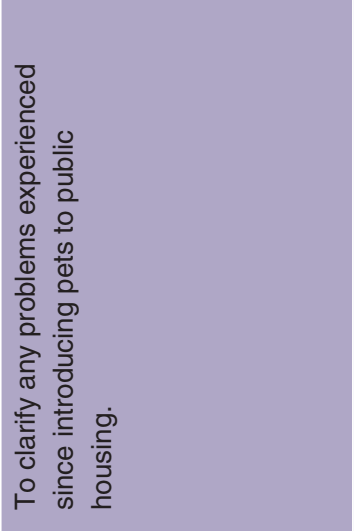 & 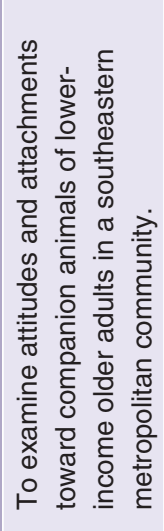 & 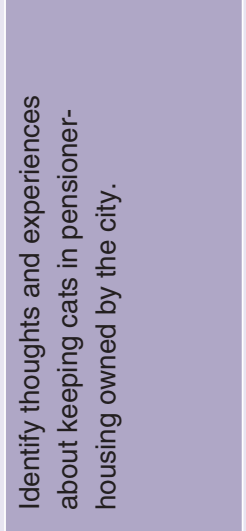 & 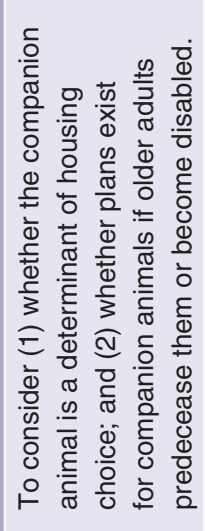 & 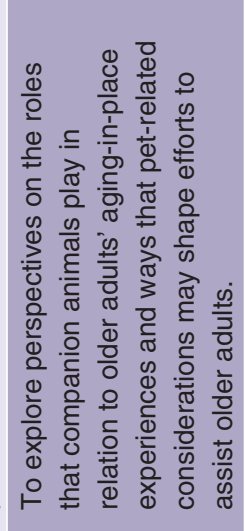 & 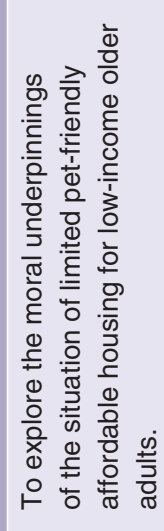 \\
\hline 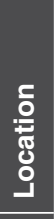 & D) & $\stackrel{0}{J}$ & 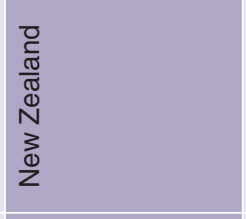 & $\stackrel{\mathscr{S}}{\mathcal{S}}$ & $\begin{array}{l}\frac{\pi}{0} \\
\frac{\pi}{\pi} \\
0 \\
0\end{array}$ & $\begin{array}{l}\frac{\pi}{0} \\
\frac{\pi}{\pi} \\
0 \\
0\end{array}$ \\
\hline $\begin{array}{l}\text { 훌 } \\
\text { के }\end{array}$ & 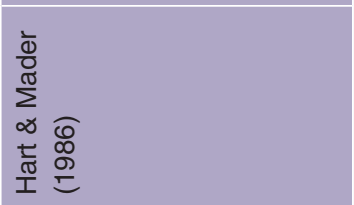 & 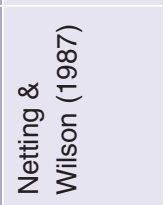 & 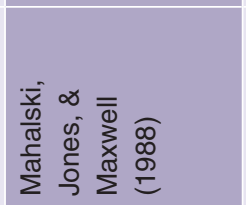 & 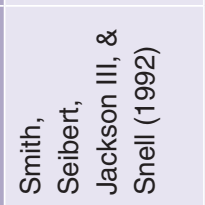 & 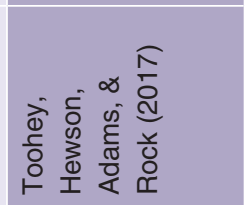 & 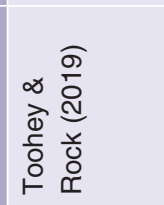 \\
\hline
\end{tabular}


was the effort to gain actual experiences of older adults with companion animals and rental housing situations or transition to them, from older adults or housingrelated professionals. The most recent study captured older adults' experiences of needing pet-friendly housing through use of vignettes (Toohey \& Rock, 2019).

\section{What is known from the existing literature?}

Existing work spans close to 40 years, from three different countries, and these studies report that pet-friendly affordable housing is limited for older adults due to restrictive leasing. Restrictive leasing in these studies refers to a leasing contract that includes a "no pet" clause. This is an extra barrier when affordable housing is limited. Although limited availability of affordable housing is not a concern for older adults only, this situation has not improved although positive effects on individuals are widely noted, especially when they face declining social support as they get older. Also, the situation has not improved despite the fact that in the US, federal laws in 1983 gave older adults the right to live with companion animals in federally funded housing.

We also learned that companion animals play a significant role in older adults' decisions on housing. Hart and Mader (1986), Mahalski et al. (1988), and Toohey, Hewson, Adams, and Rock (2017) reported that older adults without companion animals did not object to others having pets in housing complexes. Managers of US housing complexes found that having pets in their buildings did not cause more problems; rather, they found some positive outcomes.

All studies acknowledged that many older adults considered companion animals as family members and significant others. Nevertheless, most did not have plans about predeceasing their companion animals (Smith, Selbert, Jackson, \& Snell, 1992).
Although earlier work linked to particular federal law in the US (Hart \& Mader, 1986; Netting \& Wilson, 1987; Smith et al., 1992) and municipal by-laws in Aotearoa New Zealand that concern older adults (Mahalski et al., 1988), it is only recently that studies linked general aging policies such as aging-in-place and age-friendly-cities with the limited access to affordable housing (Toohey et al., 2017; Toohey \& Rock, 2019). Among these six publications, we found that the contributions made by social work scholars were relatively few.

\section{Discussion}

Our scoping review found that "restrictive leasing" with "no pets" clauses is a significant housing issue for older adults with companion animals in communities. However, these studies are scarce and contributions from social work are limited, in spite of the fact that the issues concern a large number of older adults and also are relevant and significant for social work practice and policy. We will explore how social work can contribute in the future based on the discussion.

We searched peer-reviewed work from 1980 to 2019. A disturbing fact emerged in this scoping study: the situation of restrictive leasing has not improved over 40 years. Studies continue to report that older adults with companion animals face difficulties in finding appropriate housing for both and that some relinquish companion animals, others stay put in less than ideal housing situations and some others face eviction. All studies looked at older adults with low income and highlight the fact that affordable housing is limited for them, especially when they wish to live with their companion animals and refuse to relinquish them. Many consider their relationships with companion animals to be extremely significant. For example, Toohey and Rock (2019) report that one of their older participants expressed that, if he had to, he would choose to be homeless with his companion animal rather than abandon him. This important 
issue affecting both nonhuman animals and older adults appears to have been sidelined by burgeoning studies that focus on AAI, AAT and AAA with older adults; despite the fact that the significant benefits of long-term companion animals for older adults have been recognised beyond the context of these temporary therapeutic relationships between animals and older adults. Furthermore, although such positive benefits from relationships between older adults and companion animals have become common knowledge among social workers, according to several survey studies in the US and Canada in the last 10 years (Chalmers et al., 2020; Hanrahan, 2013; Matsuoka, Sorenson, Ferreira, Hanrahan, \& Chalmers, 2019; Risley-Curtiss, 2010), such awareness and knowledge have not been translated into challenging restrictive leasing and advocating for older adults with companion animals.

Interestingly, while restrictive leasing has continued during this 40-year period, we have seen positive statutory changes in the US: for example, the introduction of 1982 California state policy and 1983 US federal policy gave rights to older adults with companion animals to live in state-funded and federally assisted housing respectively. One might think that these policy changes would influence the situation of restrictive leasing positively. However, Smith et al. (1992, p. 182) observed concerning the status of the federal law: "[t]his law ... has been little implemented." They explained why: "The HUD [the Housing and Urban Development] rules provide that state and local laws and even safety and sanitary regulations imposed by the housing facilities themselves have precedence over the federal law." They concluded that the law did not improve housing security for older pet owners. One may wonder why local laws or regulations become barriers for changing restrictive leasing for older adults while the benefits to them of having companion animals are widely known. Some studies from our scoping review mentioned that those opposed to having companion animals said that pets cause sanitary problems, allergies, noise, personal injury, neighbourhood problems or property damage (Hart \& Mader, 1986). Such negative views toward pets seem widespread. For example, a 2005 survey study in the US with renters of all ages and landlords in the private housing market found the majority of landlords cited property damage as a main reason for restrictive leasing, even among landlords who have never allowed pets (Carlisle-Frank, Frank, \& Nielson, 2005). Similar findings were observed in Australia as well (Power, 2017).

Contrary to the bias toward companion animals, the study by Carlisle-Frank et al. (2005) found no statistically significant differences in damage between renters with companion animals and those without. Instead, it reported that companion animals caused less damage than children did. The studies in our scoping review reported that problems with pets may happen but they are rare and can be managed well (Hart \& Mader, 1986; Mahalski et al., 1988;

Smith et al., 1992; Toohey et al., 2017). Yet, landlords continue to assume that pets cause problems without basing this on any evidence or experience. In such a way, a discourse of pets as problems is upheld regardless of absence of evidence or recognition of the benefits they bring. Similarly, Power (2017) found that, in Australia, landlords who never allowed pets and never experienced problems still hold negative views toward renters with pets; she argued that their unfounded view stems from the discourse of risk in a neoliberal society. Two puzzling situations seem to persist in restrictive leasing: 1) lack of progress in availability of affordable housing for older adults for the last 40 years in spite of the widespread knowledge of positive impact of pets on older adults and, in the case of the US, in spite of the fact that the rights of older adults to public housing there were granted and 2) the prevalent acceptance of pets as problem or risk discourse. We would like to examine these by utilising a Critical Animal Studies perspective and trans-species social justice framework. 
A couple of studies in particular among those in the scoping review reported findings that are helpful to begin. A study by Mahalski et al. (1988) in Aotearoa New Zealand compared the situation in a city where older adults were able to keep cats as their companions in subsidised housing, with housing in a different city where they could not keep one. The authors observed that people who are negative towards cats had never actually lived with one (Mahalski et al., 1988). Other useful findings are from Hart and Mader's (1986) study. They inquired if any issues arose after the introduction of 1982 California state's petfriendly policy on public housing; they found that the majority of housing managers / administrators did not have problems with the legislative changes. The study found that clear and enforced pet policies and use of community resources to support pet ownership helped to keep complaints at a minimum. They also found that those housing managers/administrators who were negative toward the new legislation in California had limited experience and contact with pets in their buildings. Thus, the study observed that the positive outcome did not simply happen; rather, when the housing managers / administrators took the matter seriously, let older adults know about the policies and regulations, kept close contact with them, learned about older tenants and their companion animals and provided resources to them which helped prevent or address issues.

When these findings and the aforementioned findings from Carlisle-Frank et al. (2005) and Power (2017) are considered together, one may argue that negative views toward pets seem to be related to limited contact with pets. In contrast, studies we found in the scoping review acknowledged that many older adults recognised the intrinsic value of their companion animals, their agency and personhood rather than seeing them as commodities which can be discarded at an owners' convenience. They accepted who they are and that the lives of other animals matter to both older adults and the animals themselves. When one does not have much contact with companion animals, it is easy to act based on unfounded notions about "other animals" and stigma against "other animals" which devalues them. That is speciesism.

If one does not have much contact with those who are devalued (in this case, companion animals), practice and ideology are accepted without question and one does not examine the consequences of taken-forgranted institutional oppression which is based on speciesist practice and ideology. Consequences are serious. Housing is important in aging policy such as aging-inplace; however, older adults with companion animals face a shortage of adequate and affordable housing. Another consequence is that, although companion animals are significant others for many older adults, because they are not human animals, they are not considered equally significant and older adults often need to make impossible decisions to choose housing or companion animals. Results for those animals may be lethal if they are sent to shelters and not rehomed.

Yet, in many cases, these animals have spent more time with those older adults than have any human animals and the relationships are profound. Brooks, Rushton, Lovell, McNaughton, and Rogers (2019) report that companion animals provided people with a diagnosis of severe mental illness secure, stable and intimate relationships which human therapeutic agents could not. Although that study is not about older adults, one may speculate that in a similar vein, companion animals provide such secure and stable significant relationships to older adults that humans cannot. Speciesism enables creation of a hierarchy and human exceptionalism, devaluing other animals and what they contribute, and makes it possible to sustain the discourse of pets as problems or risks. As a result, companion animals are excluded from housing and restrictive leasing continues for low-income older adults with companion animals. 
Important proposed interventions to change restrictive leasing exist. Noting that the 1981 National White House Conference on Aging acknowledged that having companion animals is a "civil right" and recognising the important physical and mental benefits of having such companions, Huss $(2005,2014)$ calls for greater allowance for animals in rental housing, along with support in terms of education about available resources, design features, and efforts to ensure positive trans-species relationships. Toohey and Krahn (2017) advocate for more affordable housing for older adults with companion animals and protection of the right to live with these animals, including elimination of housing rules that exclude animals and improved animal-protection legislation. Considering significant relationships with companion animals, the changing meaning of companion animals in human-animal relations, and the European Convention of Human Rights, Rook (2018) argues that law reform must be implemented to ban restrictive leasing in the UK as has happened in Ontario, Canada. However, while restrictive leasing is illegal in Ontario, people with companion animals still find it difficult to secure rental housing there. Contrary to discourse that constitutes pets as problems or risks, Carlisle-Frank et al. (2005) found that renting to people with companion animals is more profitable and makes better economic sense; thus, educating landlords is crucial. These proposed measures are essential but may not be sufficient to change the situation.

In order to understand the situation further and perhaps expose assumptions which are taken as normality, we explore the social construction of space. An examination of taken-for-granted speciesism is core to Critical Animal Studies. Related to this, Critical Animal Studies considers that examination of space in relation to political and economic systems is vital to understanding humananimal relations and establishing trans-species social justice (Nibert, 2002, 2013; Sorenson \& Matsuoka, 2019).
Recent studies on canine-human relations shed further light on the situation.

Armbruster (2019) contends that, although many people regard companion animals (dogs) as family members, consider them as having agency and treat them as such in their homes, once they step outside of these private spaces, dogs represent filth, dirt and the uncivilised in need of control by civilised human animals in public space. Such convictions operate to justify the discourse of dogs (i.e., pets) as problems and risks to humans. Accordingly, they are excluded from public space such as restaurants, as they are viewed as dangers to public health and sanitation (even though problems of contamination due to the presence of dogs in restaurants are minimal) and public space is constructed as being for humans alone and not for other animals (Armbruster, 2019). Such demarcations and conceptualisations of public space are not universal, rather they seem to be a result of colonialism, imperialism and neoliberal globalisation (Sorenson \& Matsuoka, 2019). For example, the situations of street dogs in Bali (McCreanor, McCreanor, \& Utari, 2019) and in Turkey (Heart, 2019) demonstrate that dogs have shared public space with humans for centuries yet changing political and economic systems threaten dogs' places in public. The situation in Taipei, Taiwan depicts this well. In 1996, a government policy of "garbage-does-not-touch-theground" was introduced to make the streets clean but this also eradicated street dogs who used to clean garbage from the street (Chang, 2019). The establishment of clean streets without roaming dogs (both of which are important signifiers in representations of a global city) and the commodification of dogs as pets changed the space which dogs can occupy from public spaces, such as streets, to private homes.

This is not an accident; political economic systems which depend on other animals (Noske, 1997; Sorenson, 2010; Wolch \& Emel, 1998) call for certain demarcations and conceptualisations of space. For example, Wallen (2019) critically examines how power 
relations were enacted through spatialisation of canine-human relations in 18th-century England. Parliament passed a Dog Tax and hierarchies of dog breeds were created while hunting was limited to the aristocracy (i.e., landlords) to protect their property (the spaces they owned and all within) from the working class (Wallen, 2019). To achieve this, all dogs belonging to working-class people were considered as hunting dogs. Subsequently, it was only the aristocracy/ landlords who could claim their dogs as companions (Wallen, 2019). These rules and practices specified who could keep dogs and where, which helped demarcate not only space but the class system. In this sense, manipulated representations of dogs manufactured particular canine-human relations which enabled broader political and economic systems.

We can identify similar operations concerning species, space, control and power in our discussion of housing for older adults with companion animals. If companion animals do not belong to public space, they should have access to private spaces such as homes. In the current scoping review, studies examined situations related to public housing or other rental housing. Such housing constitutes homes for older adults, yet this space is not private enough to house companion animals. This also seems to be true for other rental situations for any age groups (Graham, Milaney, Adams, \& Rock, 2018; Power, 2017). This indicates that the conceptualisation of private space for companion animals does not include rental housing but only privately owned housing belonging to their "owners." In other words, property ownership regulates space and the possession of dogs. Today, unlike 18th-century England, it is considered discriminatory to deny the possession of companion animals to people because of class (i.e., a lack of property ownership), yet it continues. Even when older renters' rights to possess pets in the public housing space are legally protected, speciesist discourse of pets as problems or risk trumps them. Takenfor-granted classism seems to persist as the normality of speciesism goes unquestioned. Thus, among the consequences of speciesist institutional oppression on older adults with companion animals are a lack of affordable housing and a systematically maintained class hierarchy.

On the other hand, consequences of taken-for-granted speciesist institutional oppression on companion animals can be fatal. Studies on relinquishing companion animals consistently report that rental, moving or housing issues are among the most common reasons for surrendering animals (Carter \& Taylor, 2017; Coe et al., 2014; DiGiacomo, Arluke, \& Patronek, 1998; Dolan, Scotto, Slater, \& Weiss., 2015; New et al., 1999; New et al., 2000; Salman et al., 1998; Shore, Petersen, \& Douglas, 2003) and these are closely related to housing rules and landlord restrictions (Carter \& Taylor, 2017; Coe et al., 2014; New et al., 1999; Shore et al., 2003). Studies on relinquishing companion animals grew since 2000 (Coe et al., 2014) as serious ethical concerns about euthanising healthy animals were recognised (Coe et al., 2014; Lambert, Coe, Niel, Dewey, \& Sargeant, 2019). If one dismisses such fatal outcomes as insignificant, one is not only exercising speciesism against the sanctity of life but also ignoring intersectional oppression of speciesism and classism.

\section{Implications}

Restrictive leasing depends on unquestioned speciesism and classism. If we wish to make affordable housing available to low-income older adults with companion animals, legal changes and education efforts need to be accompanied by understanding of intersectional oppression of speciesism and classism. Contributions by social work on this topic should reflect the goal of the profession, i.e., achieving social justice. We seldom hear of speciesism in social work literature today despite the important critique by Wolf (2000) 20 years ago. Discussions of institutional oppression and social justice in social work focus on human animals alone (Matsuoka \& Sorenson, 
2013, 2014). This may reflect the dominant theoretical approach on human-animal relations which emphasises individualistic human-animal bonds. A Critical Animal Studies approach, as demonstrated here, will be useful to unveil intertwined systemic oppressions to explore social justice beyond species, trans-species social justice (Matsuoka \& Sorenson, 2014). In order for social workers to understand complex intersectionality, we need to include transspecies social justice, speciesism and a Critical Animal Studies perspective in social work education.

\section{Conclusion}

This scoping review on housing, older adults and companion animals from 1980 to 2019 found that restrictive leasing ("no pets" for rental housing) among low-income older adults with companion animals in public housing persists and prevents them from accessing affordable housing. Adopting a Critical Animal Studies perspective and trans-species social justice framework, we utilised the concept of speciesism to analyse the persistence of restrictive leasing which was justified by a discourse of pets as problems or risk. Intersectional institutional oppression of speciesism and classism emerged as a root cause of restrictive leasing among these older adults. Justice for older adults cannot be achieved without due justice to their companion animals. Future studies on this topic, especially from social work, need to incorporate ideas of transspecies social justice and speciesism in the conceptualisation of human-animal relations. This requires an examination of speciesism in social work education as a "must", not because other animals are useful to humans but because such an examination helps us to understand complex intersectional oppression and to achieve justice beyond humans.

Acknowledgment. The work reported here is supported by research grants from the Social Sciences and Humanities Research Council (816-98-0042).
Accepted: 17 September 20, 2020

Published: 15 December 2020

\section{References}

Adams, C. J. (2010). The sexual politics of meat. Bloomsbury.

Adams, C. J., \& Gruen, L. (Eds.). (2014). Ecofeminism: Feminist intersections with other animals \& the earth. Bloomsbury.

American Pet Products Association. (2020). 2019-2020 National Pet Owners Survey. Retrieved from https:// www.americanpetproducts.org/pubs_survey.asp

Arksey, H., \& O'Malley, L. (2005). Scoping studies: Towards a methodological framework. International Journal of Social Research Methodology, 8, 19-32.

Armbruster, K. (2019). Dogs, dirt, and public space. In J. Sorenson \& A. Matsuoka (Eds.), Dog's best friend?: Rethinking human-canid relations (pp.113-134). McGill \& Queen University Press.

Boat, B. W., \& Knight, J. C. (2001). Experiences and needs of adult protective services case managers when assisting clients who have companion animals. Journal of Elder Abuse \& Neglect, 12(3-4), 145-155. doi:10.1300/J084v12n03_07

Brooks, H., Rushton, K., Lovell, K., McNaughton, R., \& Rogers, A. (2019). "He's my mate you see": A critical discourse analysis of the therapeutic role of companion animals in the social networks of people with a diagnosis of severe mental illness. Medical Humanities, 45(3), 326. doi:http://dx.doi.org.ezproxy.library.yorku.ca/10.1136/ medhum-2018-011633

Canadian Animal Health Institute (CAHI). (2019). Latest Canadian pet population figures released. Retrieved from https://www.cahi-icsa.ca/press-releases/latestcanadian-population-figures-released

Carlisle-Frank, P., Frank, J. M., \& Nielsen, L. (2005). Companion animal renters and pet-friendly housing in the US. Anthrozoös, 18(1), 59-77.

Carter, J., \& Taylor, C. (2017). Socio-economic factors in companion animal relinquishment on the sunshine coast, Australia. Society \& Animals. https://doi. org/10.1163/15685306-12341473

Chalmers, D., Dell, C., Dixon, J., Rohr, B., Dowling, T., \& Hanrahan, C., (2020). Recognizing animals as an important part of helping: A survey exploring knowledge and practice among Canadian social workers. Critical Social Work, 21(1). Retrieved from https://ojs.uwindsor. ca/index.php/csw/article/view/6224/5102

Chang, C. (2019). Gone stray: A journey of gou mama and their fur-kids. In J. Sorenson \& A Matsuoka (Eds.), Dog's best friend?: Rethinking human-canid relations (pp. 209-229). McGill \& Queen University Press.

Coe, J. B., Young, I., Lambert, K., Dysart, L., Nogueira Borden, L., \& Rajić, A. (2014). A scoping review of published research on the relinquishment of companion animals. Journal of Applied Animal Welfare Science, 17(3), 253-273.

DiGiacomo, N., Arluke, A., \& Patronek, G. (1998). Surrendering pets to shelters: The relinquisher's perspective. Anthrozoös, 11(1), 41-51. https://doi.org/10.1080/08927936.1998.11425086 
Dolan, E. D., Scotto, J., Slater, M., \& Weiss, E. (2015). Risk factors for dog relinquishment to a Los Angeles municipal animal shelter. Animals, 5(4), 1311-1328.

Donovan, J. (2018). Animal ethics, the new materialism, and the question of subjectivity, In Matsuoka, A. \& Sorenson, J. (Eds). Critical Animal Studies: Toward TransSpecies Social Justice. 257-274. Rowman \& Littlefield International.

Dorfman, J., Denduluri, S., Walseman, K., \& Bregman, B (2012). The role of complementary and alternative medicine in end-of-life care. Psychiatric Annals, 42(4), 150-155. doi:http://dx.doi.org/10.3928/0048571320120323-09

Ebenstein, H., \& Wortham, J. (2001). The value of pets in geriatric practice: A program example. Journal of Gerontological Social Work, 35(2), 99-115.

Engelman, S. R. (2013). Palliative care and use of animalassisted therapy. Omega: Journal of Death and Dying, 67(1-2), 63-67. doi:http://dx.doi.org/10.2190/OM.67.1-2.g

Gee, N., \& Mueller, M. (2019). A systematic review of research on pet ownership and animal interactions among older adults. Anthrozoös, 32(2), 183-207. doi:http://dx.doi.org/10.1080/08927936.2019.1569903.

Geisler, A. M. (2004). Companion animals in palliative care: Stories from the bedside. American Journal of Hospice \& Palliative Medicine, 21(4), 285-288. doi:http://dx.doi. org/10.1177/104990910402100411

Graham, T. M., Milaney, K. J., Adams, C. L., \& Rock, M. J. (2018). "Pets negotiable": How do the perspectives of landlords and property managers compare with those of younger tenants with dogs? Animals, 8(3), 32-45.

Growth From Knowledge. (2015). 61\% of Canadians own a pet: GfK survey. Retrieved from https://www.gfk.com/enus/press/61-of-canadians-own-a-pet-gfk-survey

Gruen, L. (2007). Empathy and vegetarian commitments. In J. Donovan \& C. Adams (Eds.), The feminist care tradition in animal ethics (pp. 333-343). Columbia University Press.

Hanrahan, C. (2013). Social work and human animal bonds and benefits in health research: A provincial study. Critical Social Work, 14(1), 63-79. Retrieved from http://www1.uwindsor.ca/criticalsocialwork/system/files/ Hanrahan.pdf

Hart, L. A., \& Mader, B. (1986). The successful introduction of pets into California public housing for the elderly. California Veterinarian, 40(5), 17-21.

Heart, K. (2019). Caring for Istanbul's street animals: Empathy, altruism, and rage. In J. Sorenson \& A. Matsuoka (Eds.), Dog's best friend?: Rethinking humancanid relations (pp. 230-247). McGill \& Queen University Press.

Hughes, M. J., Verreynne, M. L., Harpur, P., \& Pachana, N.A. (2020). Companion animals and health in older populations: A systematic review. Clinical Gerontologist, 43(4), 365-377. doi:10.1080/07317115.2019.1650863

Huss, R. J. (2005). No pets allowed: Housing issues and companion animals. Animal Law Review, 69(11), 69-129.

Huss, R. J. (2014). Re-evaluating the role of companion animals in the era of the aging boomer. Akron Law Review, 497(2), 497-549.

Kheel, M. (2008). Nature ethics. Rowman \& Littlefield.
Koenig, T. L., Leiste, M. R., Spano, R., \& Chapin, R. K. (2013). Multidisciplinary team perspectives on older adult hoarding and mental illness. Journal of Elder Abuse and Neglect, 25(1), 56-75. https://doi.org/10.1080/08946566 2012.712856

Kogan, L. R. (2001). Effective animal-intervention for long term care residents. Activities, Adaptation \& Aging, 25(1), 31-45.

Krause-Parello C.A., \& Kolassa J. (2016). Pet therapy: Enhancing social and cardiovascular wellness in community dwelling older adults. Journal of Community Health Nursing. 33(1), 1-10. doi:10.1080/07370016.20 16.1120587

Laing, M., \& Maylea, C. (2018). "They burn brightly, but only for a short time": The role of social workers in companion animal grief and loss. Anthrozoös, 31(2), 221-232. doi:1 0.1080/08927936.2018.1434062

Lambert, K., Coe, J., Niel, L., Dewey, C., \& Sargeant, J. M. (2019). Companion-animal relinquishment: Exploration of the views expressed by primary stakeholders within published reviews and commentaries. Society and Animals, 1-22.

Le Roux, M., \& Kemp, R. (2009). Effect of a companion dog on depression and anxiety levels of elderly residents in a long-term care facility. Psychogeriatrics, 9(1), 23-26. doi:10.1111/j.1479-8301.2009.00268.x

Mahalski, P. A., Jones, R., \& Maxwell, G. M. (1988). The value of cat ownership to elderly women living alone. International Journal of Aging and Human Development, 27(4), 249-260.

Matsuoka, A., \& Sorenson, J. (2013). Human consequences of animal exploitation: Needs for redefining social welfare. Journal of Sociology and Social Welfare, XL(4), 7-32.

Matsuoka, A., \& Sorenson, J. (2014). Social justice beyond human beings: Trans-Species social justice, In T. Ryan (Ed.), Animals in social work: Why and how they matter (pp. 94-119). Palgrave Macmillan.

Matsuoka, A., \& Sorenson, J. (2018). Critical animal studies. Towards trans-species social justice. Rowman \& Littlefield.

Matsuoka, A., Sorenson, J., Ferreira, J. T., Hanrahan, C., \& Chalmers, D. (2019, June). Engaging in trans-species social justice through rethinking animal-human relations and challenging and transforming anthropocentric action. Paper presented at Canadian Association for Social Work Education, 57th Annual Conference, Vancouver.

McCreanor, M., McCreanor, S., \& Utari, A. (2019). Connected and interconnected: Bali people and Bali dogs. In J. Sorenson \& A. Matsuoka (Eds.), Dog's best friend?: Rethinking human-canid relations (pp. 160-175). McGill \& Queen University Press.

Morley, C., \& Fook, J. (2005). The importance of pet loss and some implications for services. Mortality, 10, 127-143.

Nathanson J. (2009). Animal hoarding: Slipping into the darkness of comorbid animal and self-neglect. Journal of Elder Abuse and Neglect, 21(4), 307-324.

Netting, F. E., \& Wilson, C. C. (1987). Restrictive leasing: Issues confronting the elderly and their companion animals. Journal of Gerontological Social Work, 11(3-4), 181-189.

New, J. C., Salman, M. D., King, M., Scarlett, J. M., Kass, P. H., \& Hutchison, J. M. (2000). Characteristics of shelter-relinquished animals and their owners compared 
with animals and their owners in US pet-owning households. Journal of Applied Animal Welfare Science 3(3), 179-201.

New, Jr., J. C., Salman, M. D., Scarlett, J. M., Kass, P. H., Vaughn, J. A., Scherr, S., \& Kelch, W. J. (1999) Moving: Characteristics of dogs and cats and those relinquishing them to 12 US animal shelters. Journal of Applied Animal Welfare Science, 2(2), 83-96.

Nibert, D. (2002). Animal rights/human rights: Entanglements of oppression and liberation. Rowman \& Littlefield.

Nibert, D. (2013). Animal oppression \& human violence: Domesecration, capitalism, and global conflict. Columbia University Press.

Nocella, A. J. II, Sorenson, J., Socha, K. \& Matsuoka, A. (Eds.). (2014). Defining critical animal studies: An intersectional social justice approach. Peter Lang Publishing.

Noske, B. (1997). Beyond boundaries. Black Rose.

Peak, T., Ascione, F., \& Doney, J. (2012). Adult protective series and animal welfare: Should animal abuse and neglect be assessed during adult protective services screening? Journal of Elder Abuse \& Neglect, 24(1), 37-49.

Power, E. R. (2017). Renting with pets: a pathway to housing insecurity?. Housing Studies, 3037, 1-25.

Rauktis, M. E., Lee, H., Bickel, L., Giovengo, H., Nagel, M., \& Cahalane, H. (2020). Food security challenges and health opportunities of companion animal ownership for low-income adults. Journal of Evidence-Based Social Work (United States). https://doi.org/10.1080/26408066 2020.1781726

Risley-Curtiss, C. (2010). Social work practitioners and the human companion animal bond: national study. Social Work, 55(1), 38-47.

Rook, D. (2018). For the love of Darcie: Recognising the human-companion animal relationship in housing law and policy. The Liverpool Law Review, 39(1-2), 29-46.

Ryan, T. (2011). Animals and social work: A moral introduction. Palgrave Macmillan.

Ryder, R. (1983). Victims of science: The use of animals in research. National Anti-Vivisection Society.

Salman, M. D., New, Jr., J. G., Scarlett, J. M., Kass, P. H., Ruch-Gallie, R., \& Hetts, S. (1998). Human and animal factors related to relinquishment of dogs and cats in 12 selected animal shelters in the United States. Journal of Applied Animal Welfare Science, 1(3), 207-226. https://doi.org/10.1207/s15327604jaws0103_2

Shore, E. R., Petersen, C. L., \& Douglas, D. K. (2003). Moving as a reason for pet relinquishment: A closer look. Journal of Applied Animal Welfare Science, 6(1), 39-52.

Singer, P. (1975 [1990]). Animal liberation. Ecco.

Smith, D. W., Seibert, C. S., Jackson III, F. W., \& Snell, J. (1992). Pet ownership by elderly people: Two new issues. The International Journal of Aging and Human Development, 34(3), 175-184.

Sorenson, J. (2010). Animal rights. Fernwood.

Sorenson, J. (2014). Critical animal studies: Thinking the unthinkable. Canadian Scholars' Press.

Sorenson, J. (2016). Constructing ecoterrorism: Capitalism, speciesism \& animal rights. Fernwood.

Sorenson, J., \& Matsuoka, A. (Eds). (2019). Dog's best friend?: Rethinking human-canid relations. McGill \& Queen University Press.
Toohey, A. M., Hewson, J. A., Adams, C. L., \& Rock, M. J. (2017). When places include pets: Broadening the scope of relational approaches to promoting aging-in-place. Journal of Sociology \& Social Welfare, 44, 119-145.

Toohey, A. M., \& Krahn, T. M. (2017). "Simply to be let in": Opening the doors to lower-income older adults and their companion animals. Journal of Public Health, 40(3), 661-665.

Toohey, A. M., \& Rock, M. J. (2019). Disruptive solidarity or solidarity disrupted? A dialogical narrative analysis of economically vulnerable older adults' efforts to age in place with pets. Public Health Ethics, 12(1), 15-29.

Wallen, M. (2019). Well-bred is well-behaved: The creation and meaning of dog breeds. In J. Sorenson \& A. Matsuoka (Eds.), Dog's best friend?: Rethinking humancanid relations (pp. 59-83). McGill \& Queen University Press.

Wolch, J., \& Emel, J. (Eds.). (1998). Animal geographies: Place, politics, and identity in the nature-culture borderlands. Verso.

Wolf, D. B. (2000). Social work and speciesism. Social Work, 45(1), 88-93. 